\title{
ANALISIS PERSEPSI DAN PREFERENSI KONSUMEN TERHADAP ATRIBUT KUALITAS SAYURAN KOMERSIAL DI PASAR MODERN
}

\section{CONSUMER PERCEPTIONS AND PREFERENCES AGAINTS ATTRIBUTES OF COMMERCIAL VEGETABLE QUALITY IN MODERN MARKET}

\author{
EP. Irsyad ${ }^{1 \mathrm{a}}, \mathrm{A}$. Yoesdiarti ${ }^{1}$ dan H. Miftah ${ }^{1}$ \\ ${ }^{1}$ Jurusan Agribisnis, Fakultas Pertanian, Universitas Djuanda Bogor \\ Jalan Tol Ciawi 1, Kotak Pos 35 Bogor 16720 \\ a'Korespondensi: Arti Yoesdiarti Telp: 08963019464 E-mail : arti.yoesdiarti@unida.ac.id
}

\begin{abstract}
Research aims to know consumer perceptions and preferences of commercial vegetables' quality attributes in modern market. Sampling method used was non-probability sampling. Research Method used were descriptive analysis and Chi-Square test. Result given on consumer perceptions were : (1) Potatoes: clean enough, yellow meat colour, small peel, medium size, color of rind light brown, eyes $<5$, lumps $<3$, oval. (2) Tomatoes: Fresh, water content $20-35 \%$, sourish, reddish green, rather soft, medium size, rather round. (3) Red onions: clean enough, diameter $2,5 \mathrm{~cm}$, rather sting, rather round, light purple and dark purple., enoush smooth, clove 2-3. (4) Spinach: fresh, green, smooth enough, amount of leaf is medium, size medium, size of leaf is almost the same, rather oval. While consumer's preferences were : (1) Potatoes: very clean, without lumps, yellow meat colour, sleeky smooth skin, have no eyes, medium size, color of rind light brown, oval. (2) Tomatoes: very fresh, sweet, hard, red, size medium, water content 20-35\%, ocal. (3) Red onions: size 2,5 cm, sting, smooth, dark purple, have no cloves. (4) Spinach: fresh, green, smooth, lots of leaves, size medium, equal size of leaf, rather oval, have roots. Chi-square test shows mostly attributes of quality is significantly different.
\end{abstract}

Keywords: Perceptions, Preferences, Chi-Square, Modern market

\begin{abstract}
ABSTRAK
Penelitian bertujuan untuk mengetahui persepsi serta preferensi konsumen terhadap atribut kualitas sayuran komersial di pasar modern. Metode penelitian yaitu non probability sampling. Penelitian menggunakan analisis deskriptif dan uji Chi-Square. Persepsi konsumen: (1) Kentang : cukup bersih, warna daging kuning, kulit kelupas kecil, ukuran sedang, kulit coklat muda, mata $<5$, benjolan $<3$, lonjong. (2) Tomat : segar, kadar air 20-35\%, agak asam, hijau kemerahan, agak lunak, ukuran sedang, agak bulat. (3) Bawang merah : cukup bersih, diameter 2,5 cm, agak menyengat, agak bulat, warna ungu muda dan ungu tua, cukup mulus, anakan 2-3. (4) Bayam: segar, hijau, cukup mulus, jumlah daun sedang, ukuran sedang, cukup seragam, agak lonjong. Sedangkan Preferensi: (1) Kentang : sangat bersih, tanpa benjolan, warna daging kuning, kulit licin mulus, tidak memiliki mata, ukuran sedang, kulit coklat muda, lonjong. (2) Tomat: sangat segar, manis, keras, merah, ukuran sedang, kadar air 20-35\%, lonjong. (3) Bawang merah : ukuran 2,5 cm, menyengat, mulus, merah-ungu tua, tidak memiliki anakan. (4) Bayam : segar, hijau, mulus, daun banyak, ukuran sedang, seragam, agak lonjong, memiliki akar. Uji Chi-Squre menunjukkan atribut kualitas kebanyakan berbeda nyata.
\end{abstract}

Kata Kunci : Persepsi, Preferensi, Chi-Square, Pasar modern 


\section{PENDAHULUAN}

Seiring dengan semakin berkembangnya taraf hidup masyarakat Indonesia maka kesadaran akan pentingnya mengkonsumsi sayuran semakin meningkat khususnya pada masyarakat perkotaan. Sayuran berdasarkan morfologinya dibagi menjadi sayuran daun, sayuran batang, sayuran akar, sayuran bunga, sayuran buah, sayuran biji, dan sayuran umbi. Bayam, Bawang merah, Kentang, dan Tomat merupakan contoh sayuran yang mewakili jenis sayuran tersebut. Selain itu keempat komoditas tersebut merupakan jenis sayuran komersial dan banyak dikonsumsi oleh masyarakat.

Data 5 tahun terakhir yaitu 2013-2017 menunjukan bahwa analisa tren konsumsi sayuran mengalami peningkatan setiap tahunnya. Data konsumsi bayam, bawang merah, kentang dan tomat di Indonesia dapat dilihat pada Tabel 1 .

Tabel 1 Rata-rata Konsumsi Sayuran Perkapita Indonesia Tahun 2017

\begin{tabular}{lcccccc}
\hline \multirow{2}{*}{ Jenis Sayuran } & \multicolumn{3}{c}{ Tahun (Kg/kapita/tahun) } & & $\begin{array}{c}\text { Rata-rata } \\
\text { Pertumbuhan } \\
\end{array}$ \\
\cline { 2 - 7 } & 2013 & 2014 & 2015 & 2016 & 2017 & \\
\hline Bawang merah & 2,065 & 2,487 & 2,713 & 2,826 & 2,570 & 6,16 \\
Bayam & 3,494 & 3,522 & 4,031 & 4,484 & 3,546 & 1,40 \\
Kentang & 1,564 & 1,476 & 2,284 & 2,503 & 2,220 & 11,85 \\
Tomat & 1,716 & 1,882 & 0,418 & 0,443 & 0,302 & $-23,46$ \\
\hline
\end{tabular}

Sumber : Pusat Data dan Sistem Informasi Pertanian, 2017.

Usaha pertanian harus menyesuaikan dengan keinginan konsumen dalam keinginannya terhadap kualitas sayuran yang sesuai dengan preferensinya. Selain itu, konsumen memiliki peranan penting karena memiliki persepsi berdasarkan pengalaman dan panca inderanya terhadap produk yang dikonsumsi sehingga mempengaruhinya dalam mengambil keputusan. Oleh karena itu, mengetahui persepsi dan preferensi konsumen terhadap suatu produk sayuran sangat penting.

Salah satu alternatif berbelanja bagi masyarakat perkotaan yaitu swalayan. Salah satu swalayan di Kota Bogor yang cukup tekemula, lokasi strategis dan terluas yaitu Botani Square. Botani Square dapat diakses dengan mudah dari berbagai penjuru Kota Bogor. Salah satu pusat perbelanjaan unggulan di Botani Square yaitu Giant Ekstra Botani Square yang menyediakan barang cukup lengkap dengan konsep One Stop Shoping.

Giant Ekstra Botani Square merupakan salah satu pasar modern yang menyediakan dan menjual barang-barang pokok maupun penunjang, salah satunya adalah sayuran. Sayuran yang dijual cukup bervariasi dari jenis maupun mereknya. Salah satu sayuran yang paling umum diperdagangkan dan memiliki permintaan yang cukup besar disebut juga dengan sayuran komersial. Menurut Store Manager Giant Ekstra Botani Square diantara sayuran komersial yang dijual dan masuk dalam daftar 10 besar (top range) penjualan yaitu Kentang, Tomat, Bawang merah, dan Bayam.

Menurut Store Manager Giant Ekstra Botani Square untuk komoditas dengan perlakuan suhu ruangan dan dijual curah seperti komoditas Bayam hanya tahan selama satu hari, Tomat 3 hari, dan Kentang 7 hari. Kesempatan pendapatan yang hilang (opportunity lost) dikarenakan komoditas tersebut rusak dan tidak bisa dipasarkan yang seharusnya pendapatan tersebut diperoleh Giant Ekstra Botani Square disajikan pada Tabel 2. 
Tabel 2 Data Opportunity lost Giant Ekstra Botani Square (Januari-Juni 2018)

\begin{tabular}{lccccc}
\hline Komoditas & $\begin{array}{c}\text { Total Broken } \\
\text { stock }\end{array}$ & Satuan & $\begin{array}{c}\text { Price } \\
(\mathrm{Rp})\end{array}$ & $\begin{array}{c}\text { Opportunity } \\
\text { lost }(\mathrm{Rp})\end{array}$ & $\begin{array}{c}\text { Rerata perbulan } \\
(\mathrm{Rp})\end{array}$ \\
\hline Kentang & 994,78 & $\mathrm{Kg}$ & 18.900 & 18.801 .342 & 3.133 .557 \\
Tomat & 656,6 & $\mathrm{Kg}$ & 9.900 & 6.500 .340 & 1.083 .390 \\
Bawang merah & 18,5 & $\mathrm{Kg}$ & 44.900 & 830.650 & 138.442 \\
Bayam & 1669,5 & $\mathrm{Pcs}$ & 1.500 & 2.504 .250 & 417.375 \\
\hline \multicolumn{7}{l}{ Jumlah total } & & & 28.636 .582 & 4.772 .764 \\
\hline
\end{tabular}

Sumber : Giant Ekstra Botani Square, 2018.

Data sayuran Broken stock pada 4 komoditas tersebut cukup besar. Adanya sayuran yang tidak terjual akan mengurangi keuntungan yang diperoleh pihak retail. Kesempatan yang hilang (opportunity lost) dari adanya pendapatan yang seharusnya diterima oleh pihak retail untuk 4 komoditas tersebut dari bulan Januari sampai Juni mencapai Rp. 28.636.582 atau apabila di rata-ratakan perbulannya sekitar Rp. 4.772.764. Jumlah ini cukup besar sehingga penting untuk diperhitungkan.

Pemasar perlu mempercepat waktu penjualan. Salah satu yang menjadi daya Tarik konsumen untuk melakukan pembelian yaitu dengan cara menyediakan produk sayuran yang bekualitas yang sesuai dengan preferensi konsumen. Selain itu penting bagi pemasar untuk mengetahui persepsi konsumen terhadap sayuran yang dijualnya Penelitian ini bertujuan untuk menganalisis karakteristik konsumen sayuran komersial di pasar modern dan menganalisis persepsi dan preferensi konsumen sayuran komersial di pasar modern.

\section{BAHAN DAN METODE}

Penelitian dilakukan pada bulan Juni September 2018 di Giant Botani Square Bogor, Jawa Barat. Lokasi dipilih secara sengaja (purposive) dengan pertimbangan Giant Botani Square merupakan Hypermarket yang besar dan terkemuka di Bogor.

Metode pengambilan data konsumen pada penelitian ini yaitu non probability samping dimana responden dalam populasi tidak memiliki peluang yang sama untuk diseleksi sebagai subjek penelitian. teknik analisis yang digunakan yaitu accidental sampling. Subjek dipilih berdasarkan kemudahan untuk ditemui dan sedang bebelanja sayuran.

Konsumen yang dijadikan responden pada setiap komoditas sebanyak 40 orang konsumen Ukuran sampel ini yaitu atas dasar ukuran sampel yang layak dalam penelitian yaitu antara 30 sampai 500 rersponden (Roscoe dalam Sugiyono, p.133 : 2011).

Adapun kiteria konsumen yang dijadikan responden yaitu sebagai berikut :

1. Konsumen adalah orang yang pernah mengkonsumsi sayuran yang dijual di Giant Ekstra Botani Square berupa Kentang, Bawang merah, Bayam dan Tomat

2. Konsumen membeli atas inisiatif sendiri atau konsumen yang berbelanja (bukan orang suruhan)

3. Konsumen telah berusia 17 tahun ke atas.

Pengumpulan data dilakukan dengan cara wawancara, observasi dan kepustakaan. Penelitian dilakukan dengan analisis deskriptif/kualitatif dan kuantitatif. Analisis karakteristik responden dilakukan dengan cara deskriptif. Analisis persepsi dan preferensi terhadap atribut kualitas dilakukan secara kuantitatif menggunakan statistik non parametric dengan menggunakan uji Chi-Square.

Tingkat kepentingan dianalisis dengan mencari nilai rata-rata, dan dengan mengkategorikan data. Pengkategorian dilakukan dengan cara sebagai berikut : 
1. Menentukan rentang skala

Keterangan :

$$
R S=\frac{m-n}{b}
$$

$\mathrm{m}=$ skor tertinggi pada skala

$\mathrm{n}=$ skor terendah dalam skala

b = jumlah kelas atau kategori yang dibuat

2. Kategorisasi

setelah rentang skala dibuat, selanjutnya membuat kategori berdasarkan jumlah kelas yang ditentukan. Berikut ini adalah kategorisasi yang digunakan dengan jumlah 5 kelas.

40-72 : sangat tidak penting

$72>X \geq 104$ : Tidak penting

$104>X \geq 136$ : Cukup penting

$136>X \geq 168$ : Penting

$168>X \geq 200$ : sangat penting

\section{HASIL DAN PEMBAHASAN}

\section{Karakteristik Responden}

Dari 40 responden, rata-rata berumur 45-54 tahun pada komoditas Kentang, Tomat, dan Bawang merah sedangkan pada komoditas Bayam konsumen terbesar yaitu dengan usia 25-34 tahun. Jenis kelamin rata-rata perempuan (90\%). Dominasi perempuan terhadap pembelian sayuran dikarenakan masih adanya kecenderungan di Indonesia terkait peran perempuan dalam proses pengambilan keputusan yang diakukan oleh perempuan dalam pembelian kebutuhan pokok seperti sayuran (Imaddudin, 2013)

Pendidikan responden tergolong tinggi. Konsumen dengan pendidikan dibawah SMA hanya sedikit yaitu dibawah $8 \%$. Semakin tinggi pendidikan seseorang maka ia akan memiliki semakin banyak informasi, dan semakin selektif ia dalam memilih produk yang dikonsumsinya (Noel 2009 dalam Yasmin dan Prastiwi, 2017).

Ibu rumah tangga mendominasi sebagai konsumen disemua komoditas kecuali pada komoditas Bayam yang memiliki jumlah konsumen dengan pekerjaan sebagai ibu rumah tangga dan pegawai swasta yang hampir berimbang.

Pendapatan keluarga konsumen yang membeli sayuran di Giant Ekstra Botani Square tergolong memiliki pendapatan yang tinggi ( $>9.000 .000)$.

Jumlah tanggungan keluarga konsumen sayuran Giant Ekstra Botani terbanyak yaitu memiliki tanggungan 1-2 orang pada semua komoditas yang diteliti disusul dengan yang memiliki tanggungan keluarga 3-4 orang.

Pengeluaran sayuran konsumen sayuran Giant Ekstra Botani Square perbulan cukup tinggi yaitu konsumen 100.000-499.999 pada semua komoditas dari total responden keseluruhan. Sedangkan pengeluaran sayuran konsumen $<100.000$ hanya 4 orang dari total responden.

\section{Preferensi Konsumen}

\section{Kentang}

Preferensi konsumen kentang terhadap atribut kualitas kentang memiliki selera yaitu sangat bersih, warna daging berwarna kuning, permukaan kulit licin mulus, tidak memiliki mata, memiliki ukuran kentang sedang, warna kulit coklat muda, tanpa benjolan, dan bentuk yang lonjong.

Atribut kualitas Kentang yang berbeda nyata yaitu ukuran kentang, bentuk, warna daging, warna kulit, permukaan kulit, jumlah mata dan kebersihan. Hal ini berarti hipotesis nol (Ho) ditolak dan hipotesis alternatif (Ha) diterima, oleh karena $\mathrm{X}^{2}$ hitung lebih besar dari pada $X^{2}$ tabel. Artinya, preferensi konsumen terhadap atribut kualitas (ukuran kentang, bentuk, warna daging, warna kulit, permukaan kulit, jumlah mata dan kebersihan) tidak sama atau terdapat perbedaan preferensi konsumen terhadap atribut kualitas (ukuran kentang, bentuk, warna daging, warna kulit, permukaan kulit, jumlah mata dan kebersihan).

Atribut kualitas kentang yang tidak berbeda nyata hanya benjolan permukaan. Artinya preferensi konsumen terhadap atribut kualitas benjolan permukaan 
Kentang relatif berimbang antara yang menyukai benjolan permukaan yang tidak memiliki benjoan, benjolan $<3$, benjolan 3-5, dan benjolan > 5. Hanya kebersihan yang dianggap sangat penting, sedangkan atribut lainnya dianggap penting.

\section{Tomat}

Preferensi konsumen Tomat terhadap atribut kualitas memiliki preferensi yaitu sangat segar, kadar air $20-35 \%$, rasa manis, keras, warna kulit merah, Ukuran buah sedang dan bentuk buah lonjong.

Atribut kualitas Tomat yang berbeda nyata yaitu ukuran, warna kulit, kekerasan, bentuk buah, rasa, dan kesegaran. Hal ini berarti hipotesis nol (Ho) ditolak dan hipotesis alternatif (Ha) diterima, oleh karena $\mathrm{X}^{2}$ hitung lebih besar dari pada $\mathrm{X}^{2}$ tabel. Artinya, preferensi konsumen terhadap atribut kualitas (ukuran, warna kulit, kekerasan, bentuk buah, rasa, dan kesegaran) tidak sama atau terdapat perbedaan preferensi konsumen terhadap atribut kualitas (ukuran, warna kulit, kekerasan, bentuk buah, rasa, dan kesegaran).

Atribut kualitas Tomat yang tidak berbeda nyata hanya kadar air. Artinya preferensi konsumen terhadap atribut kualitas kadar air relatif berimbang antara yang menyukai $<20 \%, 20-35 \%, 35-50 \%$ dan $>50 \%$.

Kesegaran, kadar air dan rasa adalah atribut yang dianggap sangat penting sedangkan atribut lainnya dianggap penting.

\section{Bawang merah}

Preferensi konsumen Bawang merah terhadap atribut kualitas Tomat memiliki selera atau preferensi yaitu cukup bersih dan bersih, ukuran umbi dengan diameter sekitar 2,5 cm, aroma menyengat, mulus, bentuk umbi bulat, warna kulit merah-ungu tua, tidak memiliki anakan.

Atribut kualitas Bawang merah yang berbeda nyata yaitu warna kulit, aroma, ukuran umbi, jumlah anakan dan kemulusan. Hal ini berarti hipotesis nol (Ho) ditolak dan hipotesis alternatif (Ha) diterima, oleh karena $\mathrm{X}^{2}$ hitung lebih besar dari pada $\mathrm{X}^{2}$ tabel. Artinya, preferensi konsumen terhadap atribut kualitas (warna kulit, aroma, ukuran umbi, jumlah anakan dan kemulusan) tidak sama atau terdapat perbedaan preferensi konsumen terhadap atribut kualitas (warna kulit, aroma, ukuran umbi, jumlah anakan dan kemulusan).

Atribut kualitas Bawang merah yang tidak berbeda nyata yaitu bentuk dan kebersihan. Artinya preferensi konsumen terhadap atribut kualitas (bentuk dan kebersihan) relatif berimbang antara yang menyukai kategori kebersihan Kotor (>30\%), Cukup bersih (15-30\%), Berish $(5-15 \%)$, Sangat bersih $(<5 \%)$ dan kategori bentuk bulat, agak bulat dan lonjong.

Hanya atribut kepentingan yang dianggap sangat penting oleh konsumen sedangkan atribut lainnya dianggap penting

\section{Bayam}

Preferensi konsumen Bayam terhadap atribut kualitas Bayam memiliki preferensi yaitu atribut segar, warna daun yaitu hijau, daun mulus, jumlah daun banyak, ukuran yaitu sedang, seragam, bentuk daun agak lonjong, dan memiliki akar.

Atribut kualitas Bayam yang berbeda nyata yaitu warna daun, ukuran, kesegaran, kemulusan dan bentuk daun. Hal ini berarti hipotesis nol (Ho) ditolak dan hipotesis alternatif (Ha) diterima, oleh karena $\mathrm{X}^{2}$ hitung lebih besar dari pada $\mathrm{X}^{2}$ tabel. Artinya, preferensi konsumen terhadap atribut kualitas (warna daun, ukuran, kesegaran, kemulusan dan bentuk daun) tidak sama atau terdapat perbedaan preferensi konsumen terhadap atribut kualitas (warna daun, ukuran, kesegaran, kemulusan dan bentuk daun).

Atribut kualitas Bayam yang tidak berbeda nyata yaitu akar dan jumlah daun. Artinya preferensi konsumen terhadap atribut kualitas (akar dan bentuk daun) relatif berimbang antara yang menyukai akar dengan kategori (memiliki akar dan akar sudah dipotong) dan bentuk daun dengan kategori (bulat, agak lonjong, dan lonjong). 
Kesegaran dan warna daun adalah atribut yang dianggap sangat penting sedangkan atribut lainnya dianggap penting.

\section{KESIMPULAN DAN IMPLIKASI KEBIJAKAN}

\section{Kesimpulan}

Konsumen didominasi oleh wanita $(89,87 \%)$, dan ibu rumah tangga $(46,84 \%)$. Hal ini adanya dominasi wanita khususnya ibu rumah tangga dalam pengambilan keputusan belanja keluarga. Usia, diatas 25 tahun, dan pendidikan tergolong tinggi (SMA-Pascasarjana) $(94,94 \%)$. Selain itu pendapatan keluarga > 9.000.000 $(31,65)$, tanggungan keluarga 1-2 orang $(55,69 \%)$, pengeluaran sayuran perbulan Rp. $100.000-499.999 \quad(48,10 \%) \quad$ yang mempengaruhi kepada kemampuan daya beli keluarga.

Persepsi konsumen ialah : (1) Kentang: cukup bersih, warna daging kuning, kulit dengan kelupas kecil, ukuran sedang, kulit coklat muda, mata $<5$, benjolan <3, dan lonjong. (2) Tomat : segar, kadar air 20-35\%, agak asam, hijau kemerahan, agak lunak, ukuran sedang, agak bulat. (3) Bawang merah : cukup bersih, diameter $2,5 \mathrm{~cm}$, agak menyengat, cukup mulus, dan anakan 2-3. (4) Bayam: segar, hijau, cukup mulus, jumlah daun sedang, ukuran sedang, cukup seragam, dan agak lonjong. Sedangkan Preferensi konsumen: (1) Kentang : sangat bersih, tanpa benjolan, warna daging kuning, kulit licin mulus, tidak memiliki mata, ukuran sedang, kulit coklat muda, lonjong. (2) Tomat : sangat segar, manis, keras, merah, ukuran sedang, kadar air 20-35\%, dan lonjong. (3) Bawang merah : ukuran $2,5 \mathrm{~cm}$, menyengat, mulus, merah-ungu tua, tidak memiliki anakan. (4) Bayam : segar, hijau, mulus, daun banyak, ukuran sedang, seragam, agak lonjong, dan memiliki akar

Persepsi dengan hasil berbeda nyata ialah : Kentang (kebersihan, warna daging, ukuran, wana kulit, benjolan, bentuk), Tomat (kesegaran, kadar air, rasa, kekerasan, ukuran, bentuk buah), Bawang merah: (kebersihan, ukuran, aroma, kemulusan, jumlah anakan). Bayam: (kesegaran, warna daun, kemulusan, jumlah daun, ukuran, keseragaman, dan bentuk daun). Adapun Preferensi: Kentang: (kebersihan, warna daging, permukaan kulit, Jumlah mata, ukuran, warna kulit, bentuk). Tomat: (kesegaran, rasa, kekerasan, warna kulit, ukuran, bentuk buah), Bawang merah: (ukuran, aroma, kemulusan, warna kulit, anakan). Bayam: (kesegaran, warna daun, kemulusan, jumlah daun, ukuran, keseragaman, dan akar).

\section{Implikasi Kebijakan}

1. Giant perlu menyediakan sayuran yang sesuai dengan preferensi konsumen untuk meningkatkan penjualan dan daya saing antar pasar modern yang sama-sama menjual sayuran.

2. Giant dapat mempertimbangkan profil responden sesuai hasil penelitian untuk melakukan strategi promosi tertentu.

3. Pihak supplier sebaiknya menyesuaikan produk sayurannya dengan preferensi konsumen.

\section{DAFTAR PUSTAKA}

Engel JF, Blackwell RD, Miniard PW. 1995. Perilaku Konsumen. Ed ke-6. Jilid 1 dan 2. Budiyanto, penerjemah; Jakarta: Binarupa Aksara. Terjemahan dari: Consumer Behavior.

Imaddudin, J. 2013. Analisis preferensi konsumen terhadap atribut sayuran organik di kota bogor. Bogor : Fakultas Ekonomi dan Manajemen. IPB.

Kotler P dan Keller K L. 2009. Manajemen Pemasaran. Jilid I dan II. Edisi 13. Jakarta : Erlangga

Nahraeni, W., dkk. 2017. Analisis Preferensi Konsumen Terhadap Sayuran Katuk. Jurnal Agribisains Universitas Djuanda ISSN 2550-1151 Volume $\quad 3 \quad$ Nomor 2. https://ojs.unida.ac.id/index.php/AGB/ article/view/795 
Nahraeni, dkk. 2016. Preferensi Konsumen Terhadap Sayuran Indijenes. Jurnal Agribisnis, ISSN 2550-1152 Volume 2 Nomor 2.

Novita, I., et al. 2015. Analisis Tingkat Kepuasan Konsumen Terhadap Bauran Pemasaran Bel Mart Bogor. Jurnal Agribisains Universitas Djuanda Vol. 1 No. 1. https://ojs.unida.ac.id/index.php/AGB /article/view/152/146.

Pusat Data dan Informasi Pertanian, 2017. Statistik Konsumsi Pangan Tahun 2017. Jakarta.
Sugiyono. 2014. Metode Penelitian Kombinasi. Bandung: Alfabeta.

Yasmin T. R, Prastiwi W. 2017. Analisis Konjoin Preferensi Konsumen Sayuran Hidroponik Agrofarm Bandungan Kabupaten Semarang. Jurnal Sosial Ekonomi Pertanian. I(1), 85-93. 